\title{
The Eruption Patterns of the Teeth of Nigerian Local Pigs (Sus scrofa): Profile of Deciduous Teeth
}

\author{
Okandeji, Michael E1 , Lijoka, Ayodeji $D^{2}$, Atiba, Folusho $A^{3}$, Olopade, \\ James $\mathrm{O}^{4 *}$ \\ ${ }^{1}$ Department of Veterinary Anatomy Federal University of Agriculture Abeokuta Nigeria \\ ${ }^{2}$ Department of Veterinary Anatomy Faculty of Veterinary Medicine, University of Ibadan, Nigeria \\ ${ }^{3}$ Department of Anatomy College of Medicine University of Ibadan \\ ${ }^{4}$ Department of Veterinary Anatomy Faculty of Veterinary Medicine, University of Ibadan, Nigeria
}

With 9 figures, 2 tables

\section{Abstract}

The pigs, domesticated about 6000 years ago, are highly prolific omnivores belonging to the Family Suidae and Order artiodactyla along with their other hooved counterparts. They qualify as models for various translational research studies (including dental studies) because of their anatomical and physiological similarities to humans. There is however a dearth of information as regards the deciduous dental eruption profile (sequence and timing of eruption) of the Nigerian local pigs (NLP). This study was designed to determine the deciduous eruption profile in the NLP to assist in the management of the breed and in a bid to making the NLP more obvious as suitable animal models in dental research. A total of 51 healthy piglets (from postnatal day 1) were used for this. Their oral cavities were examined every other day for 29 weeks for signs of dental eruption. Looking at Mandibular (Md)
Received March, accepted for publication July 2021

and Maxillary $(\mathrm{Mx})$ eruptions for Incisors (I), Canines (C), Premolars (P) and Molars (M). The modular sequence in the NIP was Md/ Mx I3 (at birth), $\quad \mathrm{C} \quad$ (at birth) $\rightarrow$ Md $\quad \mathrm{I}_{1} \rightarrow \mathrm{Md}$ $\mathrm{P}_{3} \rightarrow \mathrm{MxP}^{3} \rightarrow \mathrm{MxI}^{1} \rightarrow \mathrm{Md} \mathrm{I}_{2} \rightarrow \mathrm{MdP}_{4}$ $\rightarrow \mathrm{MxP}^{4} \rightarrow \mathrm{MxP}^{2} \rightarrow \mathrm{MdI}_{2} \rightarrow \mathrm{MxI}^{2}$. It was also observed that variations in eruption timing exist amongst individuals and sexes while variation in eruption sequence exists between NLP and various breeds of pigs based on the literature. The results of this study will be particularly important to farmers, and researchers into NLP especially those using pigs in Nigeria as a model for translation research.

Keywords: Deciduous teeth; Dental Eruption; Local Pigs; Nigeria

\section{Introduction}

The pig belongs to the Suidae family (Clutton-Brock, 1999) and the order Artiodactyla, along with cattle, sheep, 
goats, camels, deer, giraffes, and hippopotamuses (Huffman, 2006), with a worldwide distribution of about 500 species (Rothschild, 2004). It displays enormous phenotypic diversity in terms of shape, colour, size, production and reproduction abilities (OseiAmponsah et al, 2017; Wiener and Wilkinson, 2011; Wilkinson et al, 2013). Due to their anatomical and physiological similarities with humans, and the availability of disease models, pigs have been used as models in some biomedical and pharmacological studies (Larsen and Rolin 2004; Stembirek et al, 2012; Tudor et al, 2010; Van der Laan et al, 2010; Wang et al, 2007). The pig's oral mucosa has been used to study the process of scar-free wound healing and drug permeability (Campisi et al, 2008; Larjava et al, 2011; Mak et al, 2009). Pig models have also been used to study regenerative processes following periodontal stem cell application (Sonoyama et al, 2006), dental implantations (Nkenke et al, 2005), bone renewal research (Sun et al, 2010) and regeneration of teeth and jaw bones (Ding et al, 2010; Xu et al, 2012; Zheng et al, 2009).

The Nigerian local pigs (NLP) or the West African Dwarf pigs, are characterized by small body sizes with short foreheads, straight tails, elongated snouts and medium-sized, semi-erect ears. They have narrow body conformation with relatively long legs and slightly inclined rumps. They have predominantly black colour coats, with others being brown, white and black or patchy and spotted (Adeola et al, 2013; AU-IBAR 2015; Osei-Amponsah et al, 2017). NLPs are well adapted to local conditions and are commonly resistant to a variety of endemic parasitic and infectious diseases (Abenga and Lawal, 2005; Penrith et al, 2004).

Teeth are hard, whitish structures in the mouth of vertebrates, used for breaking down food. They are made up of tissues of varying density and hardness, such as enamel, dentine, and cementum (Romer and Parsons, 1977). These structures surround a pulp cavity which consists of neurovascular bundles (Warwick and Williams, 1973).

Mammalian dentition refers to the types (incisor, canine, premolar, and molar), shapes, number, and arrangement of teeth in the mouth of a given species, at a particular age (Angus, 2007). All pigs are diphyodonts with heterodont dentition. (Stembirek et al, 2012). The deciduous dentition of the domestic pig is made up of 28 teeth (2xincisors $3 / 3$, canine $1 / 1$, premolars $3 / 3$, molars $\%$ ), with the maxillary and mandibular third incisors and canines, being present at birth, as the needle teeth (Swindle, 2010). The deciduous teeth are thereafter replaced by a permanent set totaling $44\left(2 \times 13 / 3, C^{1} / 1, P^{4} / 4\right.$, $\mathrm{M}^{3} / 3$ ) (Tucker and Widowski, 2009). 
The eruption pattern of the deciduous teeth of several breeds of pigs have been reported, including European wild pigs (Sus scrofa) (Matschke, 1967), Yorkshire pigs (Tucker and Widowski, 2009), Large White pigs (Tonge and McCance, 1973) and Miniature breeds of pigs (Gier, 1986; Swindle, 2010; Wang et al, 2007; Weaver et al, 1969). However, no information appears to be available on the dental eruption pattern of the deciduous teeth of the NLP. The aim of this work, therefore, was to study the pattern of eruption of the deciduous teeth of Nigerian local pigs (Sus scrofa), in a continuing effort to provide baseline information on this breed of pigs, in Nigeria

\section{Material and Methods}

\section{Animals and farm selection}

Five (5) NLPs (One male and four females, aged between 18 to 24 months) were obtained from Gbogan, Ibarapa North West Local Government and Iseyin Local Government, Oyo state for this study. They were housed and adequately fed, with a combination of concentrate and brewery waste, in concrete pens at the piggery unit of the Teaching and Research farm, University of Ibadan. Water was also provided, ad libitum. All the sows were mated naturally, and the fifty-one (51) healthy piglets produced were used for this study.

\section{Methods}

Observations were made thrice in a week, from birth until the eruption of the last deciduous tooth. Piglets were firmly held in dorsal or lateral recumbency and the mouth of the piglets were gently held open to visually examine all quadrants of the dental arches (right and left maxillary, right and left mandibular). Tooth eruption was considered to have occurred with the gingival penetration and emergence of any portion of the crown (Suri et al, 2003; Tucker and Widowski, 2009).

The experiment and procedures employed were ethically reviewed and approved by the University of Ibadan-Animal Care and Use in Research Ethics Committee (UI-ACUREC).

\section{Statistical analysis}

GraphPad Prism $5^{\circledR}$ was used for statistical analysis and data expressed as Mean $\pm S$.E. Sequence of dental eruption was determined by calculating the mean values of eruption time of each tooth across all piglets and ordering the mean values in an increasing order.

\section{Results}

The mean values and range of deciduous eruptions are as stated in Table 1 and pictorial evidence of erupted teeth are seen in Figures 1-9.

Female piglets (gilts) had lower mean values for eruption time, in comparison 
to the males (barrows). Results obtained showed that $50 \%(n=5)$ of the teeth examined erupted earlier in the gilts when compared with the barrows. Similarly, the gilts completed their eruption in $60 \%(n=6)$ of the teeth, ahead of the barrows. Only $10 \%(n=1)$ of the teeth eruption was completed in the barrows, ahead of the gilts. These observations were, however, not statistically significant.

The sequence of eruption, as stated under table 1 , showed a progression from one tooth to another, based on the mean eruption time for each tooth. However, slight variations were observed in some individual piglets. Result obtained showed that $20 \% \quad(n=10)$ of the piglets erupted the first maxillary incisor $\left(\mathrm{Mxl}^{1}\right)$ before maxillary premolar $3\left(M^{2} P^{3}\right)$, while $22 \%(n=11)$ of the piglets, erupted the fourth mandibular fourth premolar $\left(\mathrm{Md} \mathrm{P}^{4}\right)$ before the second mandibular premolar ( $\left.\mathrm{Md} \mathrm{P}^{2}\right)$.

Staining of the needle teeth, from deep yellow to dark brown, was observed in some piglets, from every litter.

Bilateral polydenty of the third maxillary incisors (Fig 9) was observed in two gilts while it was observed as a left unilateral occurrence in a barrow. These supernumerary teeth were located between the maxillary canine and the third incisor teeth in all affected piglets.

\section{Discussion}

The overall chronology of deciduous dental eruptions for NLPs was observed to be different from those observed in European wild pigs (Sus scrofa) (Matschke, 1967), Yorkshire pigs (Tucker and Widowski, 2009), Large white pigs (Tonge and Mc Cance, 1973) and miniature breeds of pigs (Gier, 1986; Swindle, 2010; Wang et al, 2007; Weaver et al, 1969). A comparison of the chronology of mandibular and maxillary eruptions for deciduous teeth in different breeds of pig is shown in Table 2.

The observed difference in the timing of the eruptions may be due to genetic or environmental factors associated with the NLPs. Tucker and Widowski (2009), reported that husbandry practices and breed selection activities could have an influence on the onset of dental eruption.

Although the mean values showed no statistical differences in the eruption timing of individual tooth, the gilts had advanced eruptions for the first mandibular and maxillary incisors, the second mandibular incisor, and the mandibular and maxillary third premolar teeth, ahead of the barrows. This observation is similar to the findings of Tucker and Widowski (2009), who reported that Yolkshire gilts had early eruptions ahead of the barrows. This observation was however different from the findings reported in miniature 
pigs, where there was no sexual difference in dental eruption (Mckean et al, 1971; Weaver et al, 1969). Of the several factors thought to be responsible for delayed teeth eruption (Suri et al, 2003), systemic stress is considered to be the primary cause of teeth eruption delays in animals (Tucker and Widowski, 2009).

While Herring and Wineski (1986), showed that a relationship exists between dental development, specifically the premolars, and chewing behaviour in miniature breeds of pigs, Tucker and Widowski (2009) showed that premolar eruption had a direct relationship with the amount of time piglets spent at the creep feeder, post weaning. Therefore, early dental development in the gilts could result in increased feed intake before and after weaning. Delumeau and Meunier-Salaün (1995), suggested that gilts may have greater abilities to adapt to learning novel behaviours, including feeding, when compared with barrows.

Deciduous teeth staining in post-natal life could be intrinsic or extrinsic in origin. The fact that some piglets in this study were observed to have discoloured needle teeth a few days after birth could be due to some conditions in-utero. Intrinsic staining of dental tissues usually occurs during pre-natal tooth development and several factors including several metabolic disorders, excess fluoride intake, tetracycline administration, vitamin $D$ deficiency, or any disturbance affecting the normal development of dentine or enamel have been implicated (Tucker and Widowski, 2009). Staining of teeth has been noted in the Sinclair miniature breed of pig, although age and time of onset was not provided (Gier, 1986).

Supernumerary teeth or polydonty is thought to be of congenital origin and may result from development of excess dental lamina, an additional follicle, or an extension of the dental lamina after the deciduous, as well as the permanent follicles which may result in the formation of additional tooth germs (Lin et al, 2009, Malmsten et al, 2015). They can be found in any part of the dental arch in the oral cavity. Although the condition is thought to be uncommon in pigs, it has however been reported in wild boars (Malmsten et al, 2015). Congenital disorders such as polydonty may result in excessive wear of the teeth and predispose affected animals to dental diseases including caries and periodontitis (Malmsten et al, 2015). This may be due to reduction in interdental spaces and mechanical abrasion of fibres on the supporting gingivae.

The Nigerian local piglets in this study showed a different sequence of eruption, when compared to the Yorkshire 
piglets. In the piglets used in this study, the third mandibular premolar erupted before its maxillary counterpart, similar to what Weaver et al., (1969), reported in the Pitman-Moore strain of miniature pigs but the reverse was the case in the Yorkshire piglets. Similarly, the fourth mandibular premolar erupted immediately before its maxillary counterpart, in the Nigerian local pigs but in the Yorkshire piglets, eruption of the fourth maxillary premolar tooth occurred after the eruption of the third mandibular premolar and first maxillary incisor teeth (Tucker and Widowski, 2009). A variation was also observed in the eruption of the first maxillary incisor teeth between our local piglets and the Pitman-Moore strain of miniature swine. While the first maxillary incisors erupted after the third premolars in the Nigeria local pigs, similar to the result obtained in the Yorkshire piglets, those of the miniature pigs erupted before the premolars (Tucker and Widowski, 2009). Eruption sequence within species is thought to be an adaptive feature, hence changes in such sequence could be an indication of how breeds of such species have adapted to their environments over time (Smith, 1994).

\section{Conclusion}

This is the first study to examine the pattern of deciduous tooth eruption in the Nigerian local pigs over a period of time. These results clearly indicate that considerable variation in eruption times exists among individuals and litters and in comparison, to other breeds of pigs. In addition, observable differences in the timing of premolar eruption were found between the current study and earlier studies. This will be particularly important to researchers who will be using pigs in Nigeria as a model for translation research.

\section{Acknowledgements}

We appreciate Dr. O.A. Adebiyi of Animal Science Department, University of Ibadan for guidance on animal management.

\section{Competing interests}

The authors declare that they have no competing interests.

\section{Authors' contributions}

M.E. and A.D. raised the animals and monitored the eruption pattern daily and weekly. F.A. was involved in data interpretation. O.J.O. was involved in research design. All authors were involved in data analysis, manuscript reading and correction.

\section{References}

Abenga, J. N. and Lawal, I. A. (2005): Implicating roles of animal reservoir hosts in the resurgence of Gambian trypanosomiasis (sleeping sickness). African Journal of Biotechnology, 4: 134-137.

Adeola, A. C., Oseni, S. O. and Omitogun, O. G. (2013): Morphological characterization of indigenous and crossbred pigs in rural and peri-urban areas of Southwestern Nigeria. Open 
Journal of Animal Sciences, 3: 230235.

\section{African Union- Inter-African Bureau for Animal Resources, AU-IBAR. (2015): “Local African Pig" pp. 1-2}

Angus, S. (2007): Dentition definition, Shorter Oxford English Dictionary, 1: A-M (sixth edition), Oxford: (Oxford University Press), p. 646, ISBN 978-019-920687-2

Campisi, G., Paderni, C., Saccone, R., Siragusa, M. G., Lo Muzio, L., Tripodo, C., Giannola, L. I. and Florena, A. M. (2008): Carbamazepine trans buccal delivery: the histomorphological features of reconstituted human oral epithelium and buccal porcine mucosae in the transmucosal permeation. International Journal of Immunopathology and Pharmacology, 21: 903-910.

Clutton-Brock J. (1999): A natural history of domesticated mammals. Cambridge, U.K.: (Cambridge University Press), p. 91

Delumeau, O. and Meunier-Salaün, M. C. (1995): Effect of early trough familiarity on the creep feeding behavior in suckling piglets and after weaning. Behavioral Processes, 34:185-196.

Ding, G., Liu, Y., Wang, W., Wei, F., Liu, D., Fan, Z., An, Y., Zhang, C., and Wang, S.(2010): Allogeneic periodontal ligament stem cell therapy for periodontitis in swine. Stem Cells, 28:1829-1838.

Gier, R. E. (1986): Dentition and other oral conditions of the Sinclair strain of miniature swine. Pp 633-639 in Swine in Biomedical Research. M. E. Tumbleson, ed. Plenum Press, New York, NY.

Herring, S. W., and Wineski, L. E. (1986): Development of the masseter muscle and oral behavior in the pig. Journal of Experimental Zoology, 237:191-207.

Huffman, B. (2006): Pigs as ungulates. The ultimate ungulate website. Retrieved April 10, 2007

Larjava, H., Wiebe, C., GallantBehm, C., Hart, D. A., Heino, J. and Hakkinen, L. (2011): Exploring scarless healing of oral soft tissues. Journal of Canadian Dental Association, $77, \mathrm{~b} 18$.

Larsen, M.O. and Rolin, B. (2004): Use of the Gottingen minipig as a model of diabetes, with special focus on type 1 diabetes research. Institute of Laboratory Animal Research Journal, 45: 303-313.

Lin, Y.T., Chang, S.W. and Lin, Y.T.J. (2009): Delayed formation of multiple supernumerary teeth. Journal of Dental Sciences, 4(3):159-164 
Mak, K., Manji, A., Gallant-Behm, C., Wiebe, C., Hart, D. A., Larjava, H. and Hakkinen, L. (2009): Scarless healing of oral mucosa is characterized by faster resolution of inflammation and control of myofibroblast action compared to skin wounds in the red Duroc pig model. Journal of Dermatological Science, 56: 168-180.

Malmsten, A., Dalin, A. M. and Pettersson, A. (2015): Caries, periodontal disease, supernumerary teeth and other dental disorders in Swedish wild boar (Sus scrofa). Journal of Comparative Pathology, 153: 50-57

Matschke, G. H. (1967): Aging European wild hogs by dentition. The journal of Wildlife Management, 31:109113

Mckean, C. F., Jump, E. B. and Weaver, M. E. (1971): The Calcification pattern of deciduous teeth in miniature swine. Archives of Oral Biology, 16:639-648.

Nkenke, E., Lehner, B., Fenner, M., Roman, F. S., Thams, U., Neukam, F. W. and Radespiel-Troger, M. (2005): Immediate versus delayed loading of dental implants in the maxillae of minipigs: follow-up of implant stability and implant failures. International Journal of Oral Maxillofacial Implants, 20: 3947.

Osei-Amponsah, R., Skinner, B. M., Adjei, D. O., Bauer, J., Affara, N. A. and Sargent, C. A. (2017): Origin and phylogenetic status of the local Ashanti Dwarf pig (ADP) of Ghana based on genetic analysis. BMC Genomics, 18:193. DOI 10.1186/s12864-017$3536-6$

Penrith, M.L., Thomson, G.R., Bastos, A.D., Phiri, O.C., Lubisi, B.A., Duplessis, E.C., Macome, F., Pinto, F., Botha, B., and Esterhuysen, J. (2004): An investigation into natural resistance to African swine fever in domestic pigs from an endemic area in southern Africa. Revue Scientifique et Technique de l'Office International des Epizooties, 23: 965-977

Romer, A. S., and Parsons, T. S. (1977): The vertebrate body. (HoltSaunders International), 300-310.

Rothschild, M. F. (2004): Porcine genomics delivers new tools and results: this little piggy did more than just go to market. Genetics Research, 83:1-6.

Smith, B. H. (1994): Sequence of emergence of the permanent teeth of Macaca, Pan, Homo, and Australopithecus: its evolutionary significance. American Journal of Human Biology, 6:61-76.

Sonoyama, W., Liu, Y., Fang, D., Yamaza, T., Seo, B-M., Zhang, C., Liu, H., Gronthos, S., Wang, C.Y., Wang, S. and Shi, S. (2006): Mesenchymal stem cell-mediated functional tooth regeneration in swine. PLoS One 
1(1), e79. doi: 10.1371/journal.pone. 0000079

Stembirek, J., Kyllar, M., Putnova, I., Stehlik, L. and Buchtova, M.(2012): The pig as an experimental model for clinical craniofacial research. Laboratory Animals, 46: 269-279

Sun, D., Wang, J., Wu, R., Wang, C., He, X., Zheng, J. and Yang, H.(2010): Development of a novel LAMP diagnostic method for visible detection of swine Pasteurella multocida. Veterinary Research Communications, 34: 649-657.

Suri, L., Gagari, E. and Vastardis, H. (2003): Delayed tooth eruption: pathogenesis, diagnosis, and treatment. A literature reviews. American Journal of Orthodontics and Dentofacial Orthopedics, 126 (4):432-445

Swindle, M. M. (2010): Swine as models in dental and oral surgical research. Catheterization series. Sinclair bio resources LLC.

Tonge, C. H. and McCance, R.A. (1973): Normal development of the jaws and teeth in pigs, and the delay and malocclusion produced by calorie deficiencies. Journal of Anatomy, 115 (1):1-22

Tucker, A. L., and Widowski, T.M. (2009): Normal profiles for deciduous dental eruption in domestic piglets: Ef- fect of sow, litter, and piglet characteristics. Journal of Animal Science, 87: 2274-2281

Tudor, C., Bumiller, L., Birkholz, T., Stockmann, P., Wiltfang, J. and Kessler P. (2010): Static and dynamic periosteal elevation: a pilot study in a pig model. International Journal of Oral Maxillofacial Surgery, 39:897-903.

Van Der Laan J.W, Brightwell J., Mcanulty P., Ratky J. and Stark, C. (2010): Regulatory acceptability of the minipig in the development of pharmaceuticals, chemicals and other products. Journal of Pharmacology and Toxicology, 62:184-95

Wang, S., Liu, L., Fang, D. and Shi, S. (2007): The miniature pig: a useful large animal model for dental and orofacial research. Oral Diseases, 13: 530-537

Warwick, C. and Williams, P. L. (1973): Gray's Anatomy 35th ed. (W.B. Saunders Co). Philadelphia

Weaver, M. E., Jump, E. B. and Mckean, C. F.(1969): The Eruption pattern of deciduous teeth in miniature swine. Anatomical Records, 154:8186.

Wiener, P. and Wilkinson, S. (2011): Review. Deciphering the genetic basis of animal domestication. Proceedings of the Royal Society B, 278: 31613170 
Wilkinson, S., Lu, Z. H., Megens, HJ., Archibald, A. L., Jackson, I. J., Groenen, M. A. M., Crooijmans, R. P., Haley C., Ogden, R. and Wiener, P. (2013): Signatures of Diversifying Selection in European Pig Breeds. PLoS Genetics, 9(4): e1003453. doi: 10.1371/journal.pgen.1003453

Xu, J., Zheng, Z. and Fang, D.(2012):

Early stage pathogenic sequence of jaw osteoradionecrosis in vivo. Journal of Dental Research, 91:702-708.

Zheng, Y., Liu, Y., Zhang, C. M., Zhang, H. Y., Li, W. H., Shi, S., Le, A. D. and Wang, S. L. (2009): Stem cells from deciduous tooth repair mandibular defect in swine. Journal of Dental Research,88: 249-254.

Author address:

Dr. Okandeji, Michael E

jkayodeolopade@yahoo.com

Table (1): Mean \pm Standard Error of the Age of deciduous tooth eruption in the maxilla and mandible for male and female piglets of the Nigerian Local pigs $(n=51)$

\begin{tabular}{|c|c|c|c|c|}
\hline & MALES $(n=24)$ & & FEMALES & \\
\hline Tooth Eruption & Mean \pm S.E & Range & Mean \pm S.E & Range \\
\hline Md I 1 (Days) & $12.95 \pm 0.73$ & $8-18$ & $12.54 \pm 0.74$ & $7-23$ \\
\hline Mx I $I^{1}$ (Weeks) & $3.75 \pm 0.15$ & $3-5$ & $3.28 \pm 0.22$ & $2-5$ \\
\hline $\mathrm{Md} \mathrm{I}_{2}$ (Weeks) & $11.08 \pm 0.40$ & $6-14$ & $10.67 \pm 0.39$ & $5-13$ \\
\hline Mx I $I^{2}$ (Weeks) & $17.91 \pm 0.58$ & $12-24$ & $16.91 \pm 0.53$ & $12-20$ \\
\hline Md $P_{2}$ (Weeks) & $5.73 \pm 0.71$ & $3-13$ & $5.59 \pm 0.68$ & $3-13$ \\
\hline Mx P2 (Weeks) & $7.65 \pm 0.20$ & $6-9$ & $7.33 \pm 0.16$ & $6-9$ \\
\hline Md $P_{3}$ (Weeks) & $3.63 \pm 0.23$ & $2-6$ & $3.26 \pm 0.22$ & $1-5$ \\
\hline Mx $P^{3}$ (Weeks) & $3.38 \pm 0.25$ & $2-7$ & $3.19 \pm 0.24$ & $1-6$ \\
\hline Md $\mathrm{P}_{4}$ (Weeks) & $6.25 \pm 0.17$ & $4-8$ & $6.15 \pm 0.17$ & $4-7$ \\
\hline Mx $\mathrm{P}^{4}$ (Weeks) & $6.33 \pm 0.17$ & $5-9$ & $6.00 \pm 0.19$ & $5-8$ \\
\hline
\end{tabular}

The deciduous eruption sequence elucidated is as follows: $\mathbf{M d} / \mathbf{M x I 3}$ (at birth), C (at birth)

$\rightarrow \mathrm{Md} \mathrm{I}_{1} \rightarrow \mathrm{Md} \mathrm{P}_{3} \rightarrow \mathrm{MxP}^{3} \rightarrow \mathrm{MxI}^{1} \rightarrow \mathrm{Md} \mathrm{P}_{\mathbf{2}} \rightarrow \mathrm{MdP}_{\mathbf{4}} \rightarrow \mathrm{MxP}^{4} \rightarrow \mathrm{MxP}^{2} \rightarrow \mathrm{Md} \mathrm{I}_{\mathbf{2}} \rightarrow \mathrm{MxI}^{2}$

*Note: Md: Mandibular, Mx: Maxillary.

Md I1, I2, Is: Mandibular Incisors 1, 2, 3

Mx I1 $I^{2}, I^{3}$ : Maxillary Incisors 1, 2, 3

Md $\mathrm{P}_{2}, \mathrm{P}_{3}, \mathrm{P}_{4}$ : Mandibular Premolars 2, 3, 4

$\mathrm{Mx} \mathrm{P}^{2}, \mathrm{P}^{3}, \mathrm{P}^{4}$ : Maxillary Premolars 2, 3, 4

C: Canine teeth.

Maxillary and Mandibular canines and Incisor 3 teeth are present at birth. 
Deciduous teeth eruption of the Nigerian local pig.

Okandeji et al.,

Table (2): Comparison of the chronology of mandibular and maxillary eruptions for deciduous teeth in different breeds of pig

\begin{tabular}{|c|c|c|c|c|c|c|}
\hline Tooth Eruption & $\begin{array}{l}\text { Nigerian } \\
\text { Local pig }\end{array}$ & $\begin{array}{l}\text { Yorkshire } \\
\text { Pig }\end{array}$ & $\begin{array}{l}\text { Sinclair } \\
\text { Minipig }\end{array}$ & $\begin{array}{l}\text { Pitman- } \\
\text { Moore Mini- } \\
\text { pig }\end{array}$ & $\begin{array}{l}\text { European } \\
\text { Wild Hog }\end{array}$ & $\begin{array}{l}\text { Chinese } \\
\text { Minipig }\end{array}$ \\
\hline $\mathrm{Md} \mathrm{I}_{1}$ (Days) & $7-23$ & $2-11$ & $1-28$ & $1-28$ & $11-20$ & $7-21$ \\
\hline Mx I ${ }^{1}$ (Weeks) & $2-5$ & $1-5$ & $4-10$ & $7-28$ & $7-22$ & $1-3$ \\
\hline $\mathrm{Md} \mathrm{I}_{2}$ (Weeks) & $5-14$ & & $7-11$ & $7-11$ & $9-13$ & $8-21$ \\
\hline Mx $I^{2}$ (Weeks) & $12-24$ & & $11-19$ & $8-17$ & $10-17$ & $8-21$ \\
\hline Md $P_{2}$ (Weeks) & $3-13$ & & $6-12$ & $6-12$ & $9-15$ & $4-10$ \\
\hline Mx $P^{2}$ (Weeks) & $6-9$ & & $7-11$ & $5-9$ & $7-12$ & $4-10$ \\
\hline Md $P_{3}$ (Weeks) & $1-6$ & $2-6$ & $3-5$ & $3-5$ & $4-5$ & $1-5$ \\
\hline Mx $\mathrm{P}^{3}$ (Weeks) & $1-7$ & $1-2$ & $3-11$ & $1-3$ & $2-3$ & $1-5$ \\
\hline Md $\mathrm{P}_{4}$ (Weeks) & $4-7$ & $1-3$ & $1-3$ & $1-3$ & $2-3$ & \\
\hline Mx $\mathrm{P}^{4}$ (Weeks) & $5-9$ & $2-6$ & $7-11$ & $3-4$ & $6-7$ & $6-8$ \\
\hline
\end{tabular}

Fig (1): Photograph of the oral cavity with arrows showing the "Needle Teeth (Mandibular and

Maxillary)

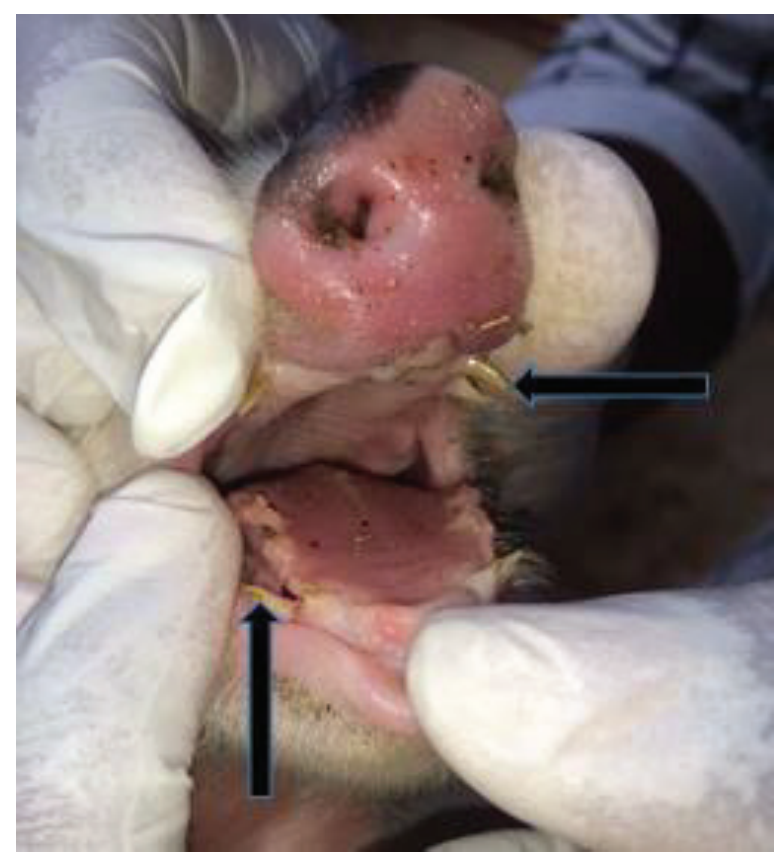




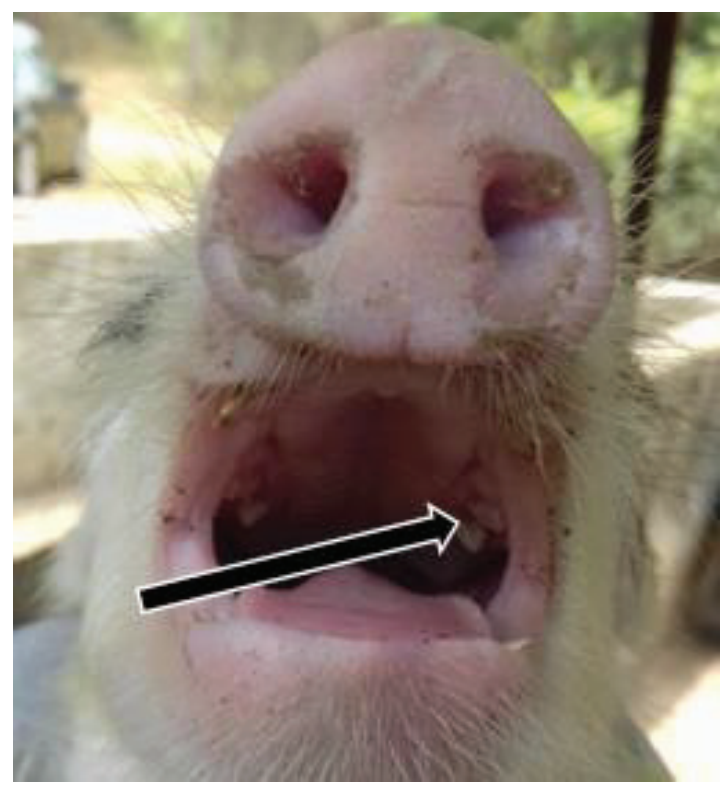

Fig (2): Photograph of the oral cavity with arrow showing erupted $M x p^{3}$

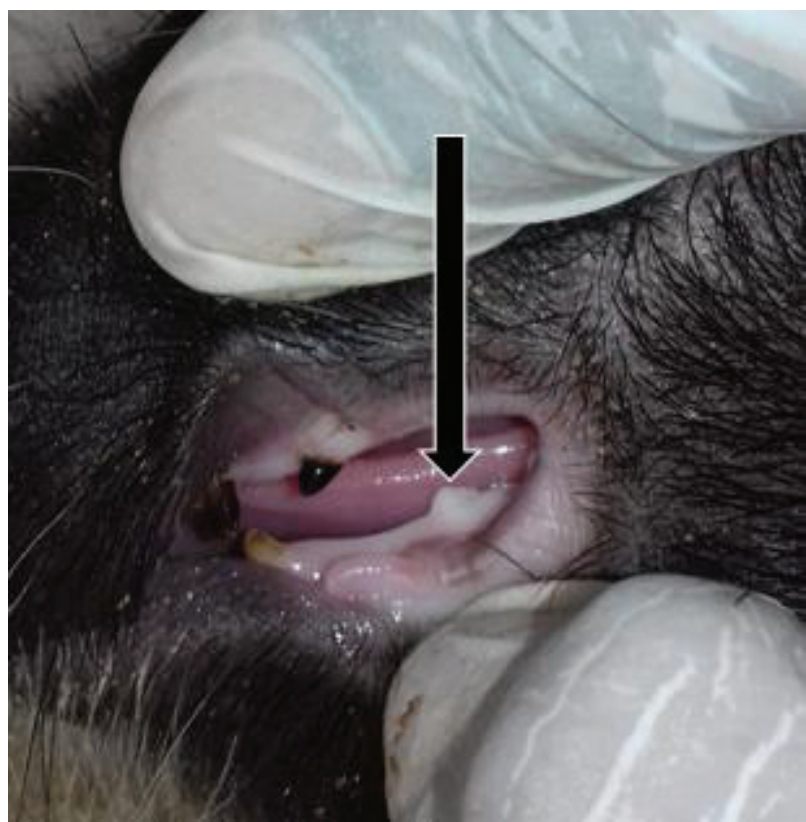

Fig (3): Photograph of the oral cavity with arrow showing erupted $M d p_{2}$. 
Deciduous teeth eruption of the Nigerian local pig.

Okandeji et al.,

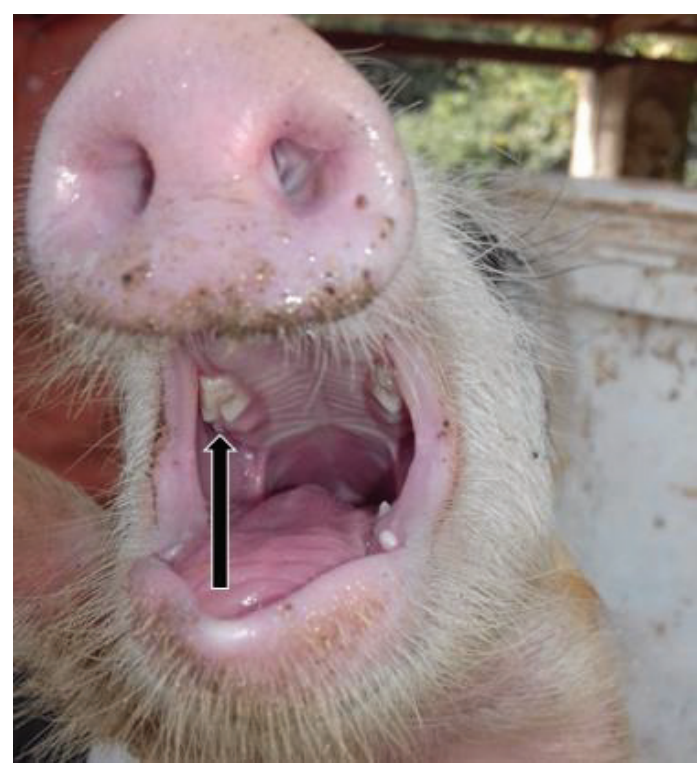

Fig (4): Photograph of the oral cavity with arrows showing erupting $M x p^{4}$.

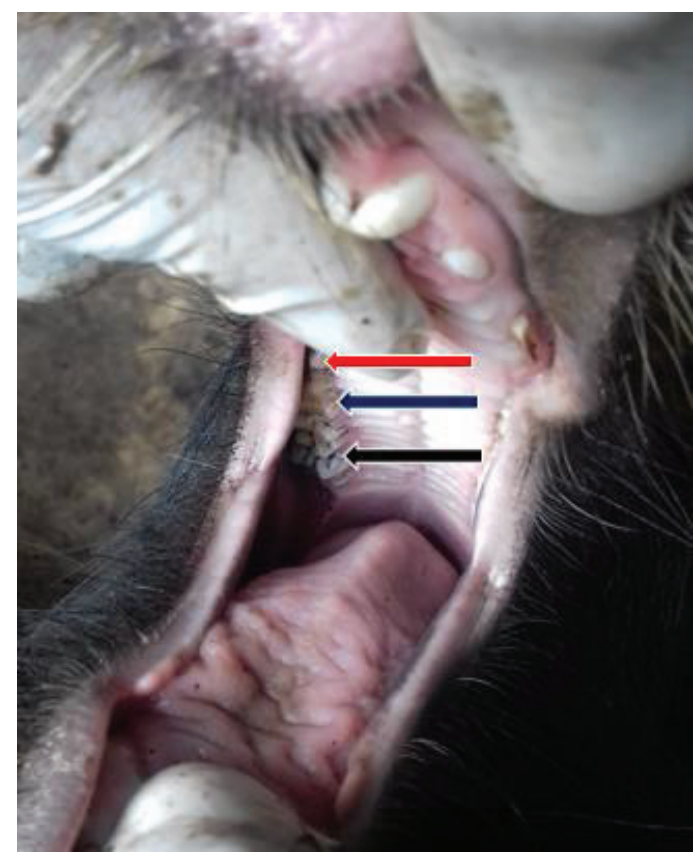

Fig (5): Photograph of the oral cavity with arrows showing $M x p^{2}$ (red arrow), $M x p^{3}$ (blue arrow) and $\mathrm{Mx} \mathrm{p}^{4}$ (black arrow). 


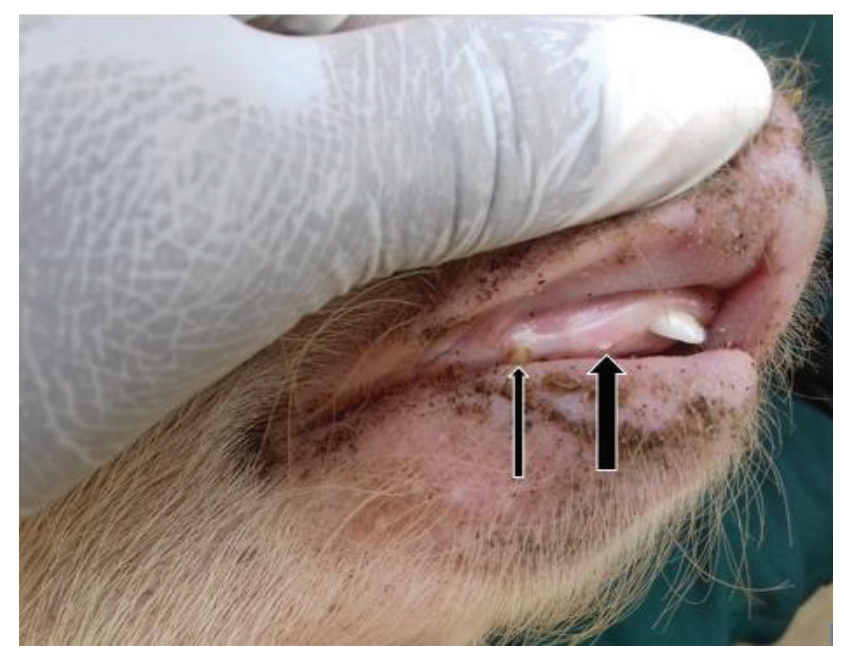

Fig (6): Photograph of the oral cavity with arrows showing $M x \mathrm{i}^{3}$ (thin arrow) and $\mathrm{Mx} \mathrm{i}^{2}$ (thick arrow).

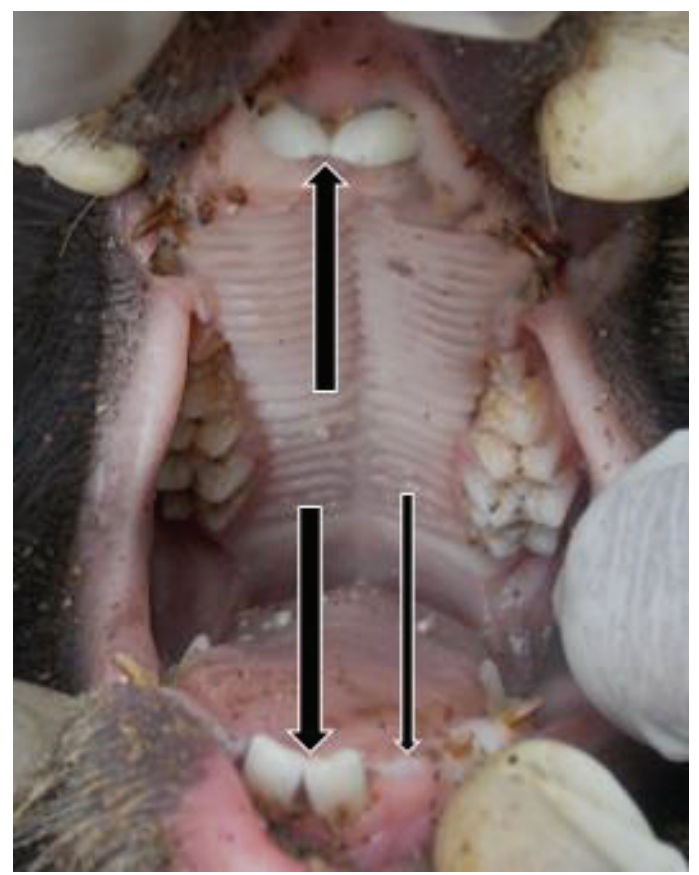

Fig (7) Photograph of the oral cavity with thick arrows show central incisors ( $M d i_{1}$ and $M x i^{1}$ ), and $\mathrm{Md} \mathrm{i}_{2}$ (thin arrow) 


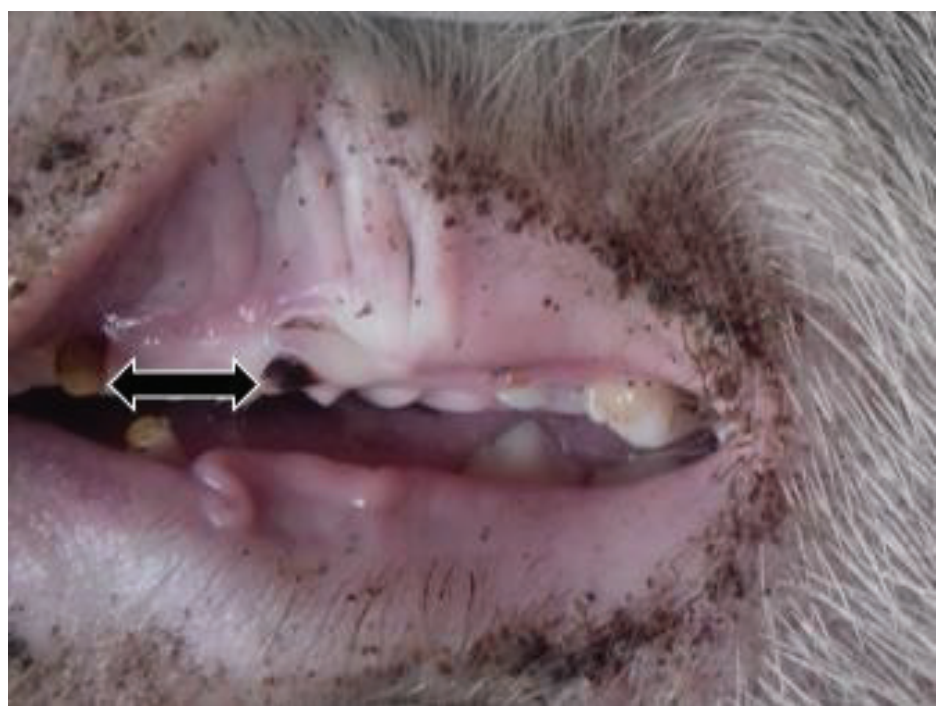

Fig (8): Photograph of the oral cavity with Left-Right arrow showing stained incisor $\mathrm{Mx} \mathrm{i}^{3}$ and canine teeth

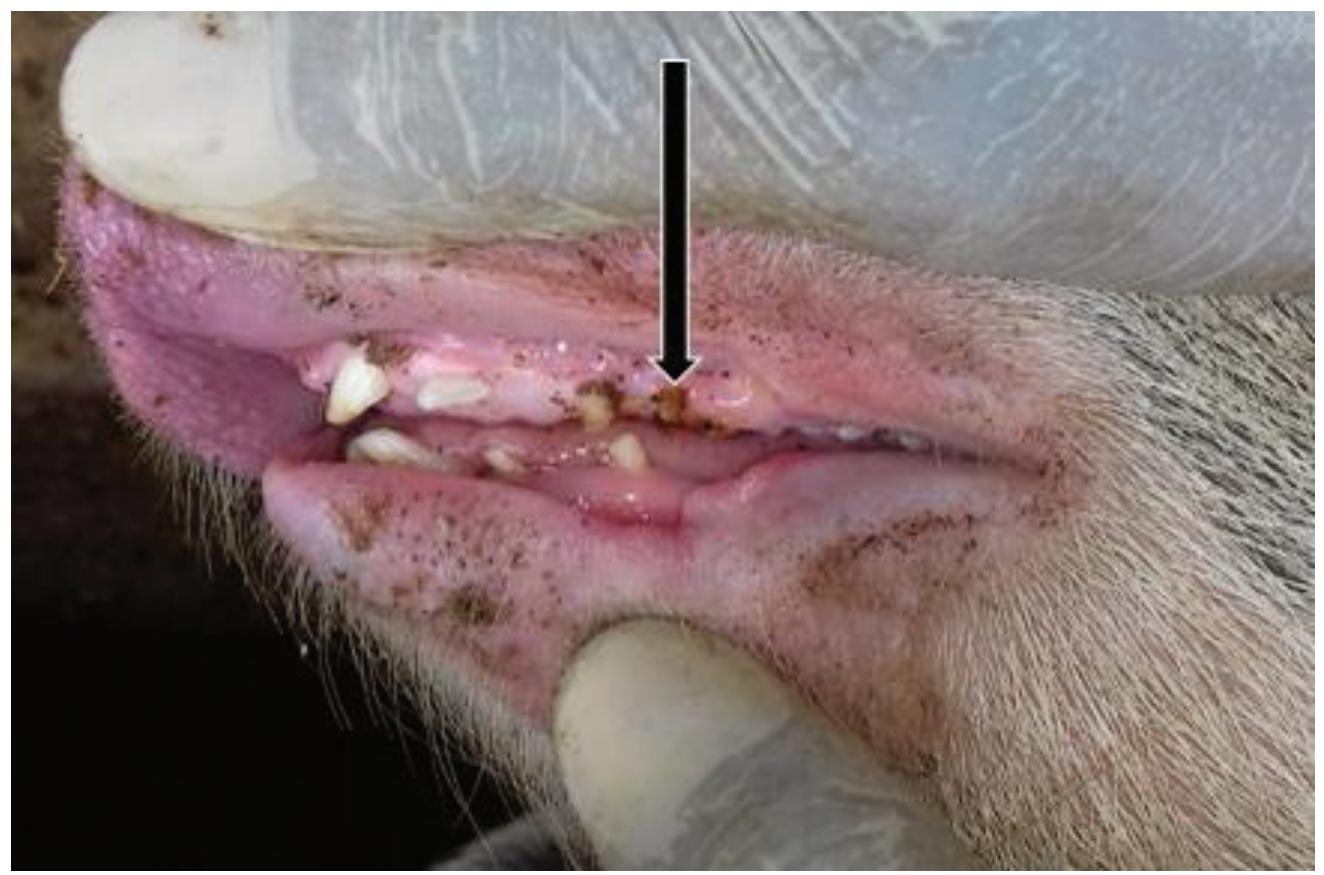

Fig (9): Photograph of the oral cavity with arrow showing polydonty of $\mathrm{Mx} \mathrm{i}^{3}$ 


\section{Animal species in this Issue}

\section{Pig (Sus scrofa)}

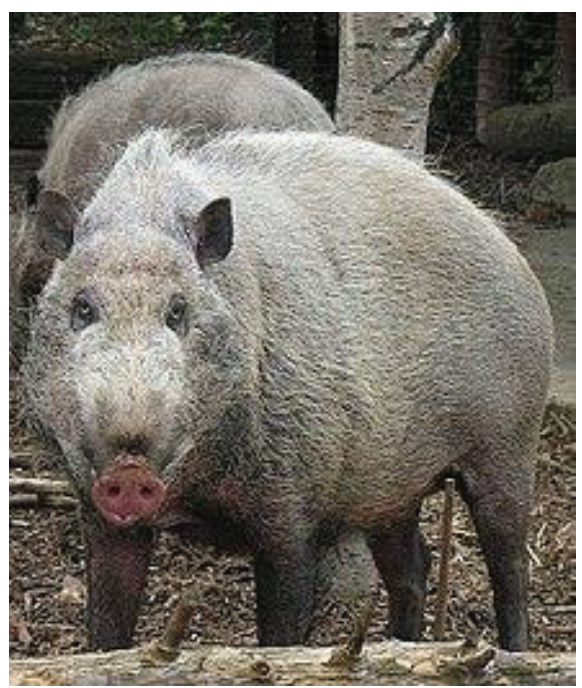

Kingdom: Animalia \& Phylum: Chordata \& Class: Mammalia \& Order: Artiodactyla \& Family: Suidae \& Subfamily: Suinae \& Genus: Sus \& Species: Sus scrofa

A typical pig has a large head with a long snout that is strengthened by a special prenasal bone and by a disk of cartilage at the tip. The snout is used to dig into the soil to find food and is a very acute sense organ. Each foot has four hoofed toes, with the two larger central toes bearing most of the weight, and the outer two also being used in soft ground.

Most pigs today are domesticated pigs raised for meat (knownas pork). Miniature breeds are commonly kept as pets. Because of their foraging abilities and excellent sense of smell, people in many European countries use them to find truffles. Both wild and feral pigs are commonly hunted.

Apart from meat, pig skin is turned into leather, and their hairs are used to make brushes. The relatively short, stiff, coarse pig hairs are called bristles, and were once so commonly used in paintbrushes that in 1946 the Australian Government launched Operation Pig Bristle. In May 1946, in response to a shortage of pig bristles for paintbrushes to paint houses in the post-World War II construction boom, the Royal Australian Air Force(RAAF) flew in 28 short tons of pig bristles from China, their only commercially available source at the time

Source: Wikipedia, the free encyclopaedia 